\title{
鉱石から始まるインジウムの世界における 物質フローの構築
}

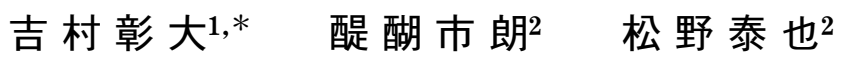

\author{
1東京大学工学部マテリアル工学科 \\ 東京大学大学院工学系研究科
}

J. Japan Inst. Metals, Vol. 75, No. 9 (2011), pp. 493-501

(C) 2011 The Japan Institute of Metals

\section{Construction of Global Scale Substance Flow of Indium from Mining}

\author{
Akihiro Yoshimura ${ }^{1, *}$, Ichiro Daigo ${ }^{2}$ and Yasunari Matsuno ${ }^{2}$ \\ ${ }^{1}$ Department of Materials Engineering, Faculty of Engineering, The University of Tokyo, Tokyo 113-8656 \\ ${ }^{2}$ Department of Materials Engineering, Graduate School of Engineering, The University of Tokyo, Tokyo 113-8656
}

\begin{abstract}
Recently, recycling of rare metals has been of great interest because of the rapid growth in their demands and maldistribution of the natural resources. Substance flow analysis (SFA) is a useful tool to figure out the flow of substance in specific regions. However, few SFA has so far been conducted for rare metals. In this paper, we focused on indium and conducted SFA of indium in Japan and global scale. The most of indium is used as Indium Tin Oxide (ITO). The end use of ITO was categorized into 2 groups; Liquid Crystal Display modules and Plasma Display Panel modules, which were further assembled to final end-use products. Quantified was the flow of indium during its lifecycle; mining and smelting, manufacturing, use and waste management. In mining and smelting, the data about the indium content in ore and production of primary metal of indium during 1999-2008 were collected. In manufacturing, we estimated the content of indium of final end-use products, and estimated the input of indium for producing ITO in Japan. Then, we extrapolated the results to SFA in global scale. In-use stock and discard of indium were estimated by dynamic SFA, in which the time-series data about the input of indium in final end-use products and their lifetime distribution were used. In this study, we estimated the loss of indium in each process as recovery potential. It was found that the extraction rate of indium in mining and smelting process was 8-11\%, and the loss of indium in the process was 4,826 t in 2004 . The amount of loss in manufacturing process was $310 \mathrm{t}$, in-use stock of indium was $115 \mathrm{t}$, and the discarded indium in end-of-life products was $5 \mathrm{t}$ in global scale in 2004. Therefore, it was concluded the biggest recovery potential of indium was in mining and smelting.
\end{abstract}

(Received April 1, 2011; Accepted May 30, 2011)

Keywords: substance flow analysis, indium, liquid crystal display, plasma display panel, recycle potential, in-use stock

\section{1. 緒言}

近年，液晶パネルを用いるデバイスが急速に普及してい る。その種類は，携帯電話から大型液晶テレビまで多岐にわ たる，液晶パネルには，透明でありながら導電性を有する透 明電極が必要となる。その材料には酸化インジウムスズ (Indium Tin Oxide: ITO)が用いられ, 近年その需要は増大 を続けている．亜鉛1)や高分子2)を用いた代替材料はまだ開 発途上にあり, 今後も In の需要は増大すると考えられる. 従って, Inの効率的な生産や回収の促進が望まれるが, 国 内外におけるInのフローや蓄積量は, 詳細には把握されて いないのが現状である.

社会における物質のフローと蓄積量の把握には, 物質フ ロー分析 (Substance Flow Analysis: SFA)が有効である. In のSFA を実施した研究は，これまでに 3 件報告されてい

\footnotetext{
* 東京大学学生 (Undergraduate Student, The University of Tokyo)
}

る.上木ら3)は, 1990 年から 2007 年にかけての日本国内に おけるInの生産状況, 供給, および需要を分析した. そし て，その結果に基づき，2007 年に日本国内で ITO 向けに投 入された Inのフローを分析し, LCD パネルの製造プロセス におけるロスを分析した. しかし，ライフサイクルに基づい た In の物質フローの解析には至っていない。 また中島ら4) は, 2004 年に製造されたフラットパネルディスプレィ (Flat Panel Display: FPD)に着目し，これらの製品生産時のフ ローを明らかにしている.しかし，分析対象としたフローは 日本に打ける単年のデータであり, 最終製品へと加工された あとのフロー分析を行っていない。一方, 遠藤ら5) は, 採 掘・製錬フローの分析結果や, 製品の需要予測などを元に, In 資源の枯渴に関して予測を行った。これは, 液晶を使用 している製品を 4 種類に限定し, それらの用途別に ITO 膜 の厚さを一律としている. また, 将来予測を主な目的として いたため, 現状の把握に対しては粗い推計となっている.

従って, Inのリサイクル可能量を評価するには, 採掘 · 製錬段階から，製品での使用および廃棄に至るまでの物質つ 


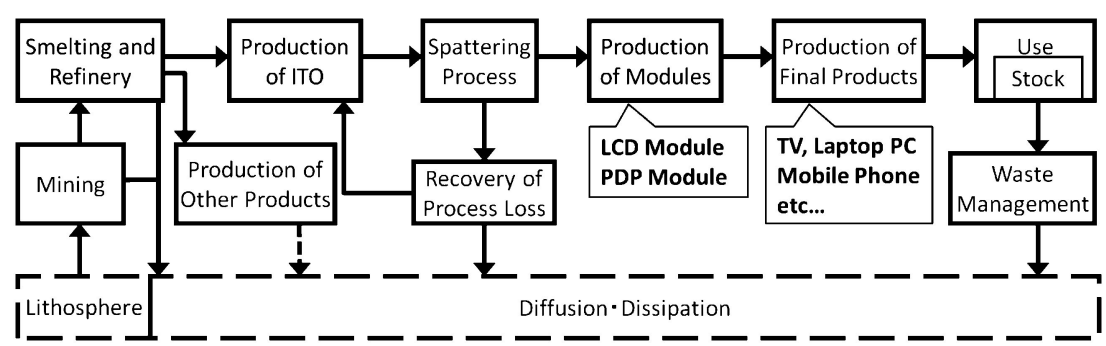

Fig. 1 System boundary of this study.

ローを把握することが望まれる。 また, 資源は世界的に取引 されていることから, 日本国内の評価の久ならず世界全体で のフローを評価する必要がある。 そこで本論文では, 日本お よび世界に抢ける，採掘・製錬から廃棄に至るまでの Inの 物質フローと蓄積量を解析し, Inのリサイクル可能量を評 価することを目的とした。

\section{2. 研 究 方 法}

\subsection{In の物質フロー}

本論文のシステム境界 (解析の対象とした工程)を Fig. 1 に示す.

Fig. 1 に示すように, In は, 採掘, 製錬され一次地金へ と加工された後, 各種用途に用いられる. 本論文では, In の用途には, ITO 膜とその他の製品に分け, ITO 膜以外の 用途に関しては, 需要量は把握するものの, その後のフロー は考慮しなかった． ITO膜向けに投入された In は，スパッ タリングプロセスを経て ITO 膜へと加工される．このプロ セスに颃いて発生するスクラップは一部が回収され, 二次地 金としてリサイクルされる. 生産された ITO 膜は, 液晶素 子, プラズマディスプレイモジュール (Plasma Display Panel Module: PDP モジュール)として加工され, 最終製品 に使用される。最終製品は, 使用段階では社会中に蓄積さ れ，寿命を迎えると廃棄される。

各工程での In フローの解析方法について, 次節より詳述 する.

\subsection{In の採掘・製錬工程におけるフロー推計}

In は $\mathrm{Zn}$ の副産物として産出されるため, $\mathrm{Zn}$ 鉱石の採掘 量, および鉱石の In 含有濃度を考えることで, 鉱石中の In 重量を推計した。

$\mathrm{Zn}$ 鉱石の採掘量は，そのものを示す統計值が得られなか った。そこで, 鉱石の $\mathrm{Zn}$ 含有濃度の平均值 ${ }^{6}$, 金属 $\mathrm{Zn}$ の 総生産量6), $\mathrm{Zn}$ の一次地金生産時の歩留まり7) から $\mathrm{Zn}$ 鉱石 の総生産量を推計した. 次に, $\mathrm{Zn}$ 鉱石中の In 当量を推計す るため, 世界での $\mathrm{Zn}$ 鉱石の平均 In 含有濃度を求めた. In 含有濃度は鉱山により異なるため, 世界中の 27 か所の鉱山 での埋蔵量, および In 含有濃度8) を加重平均した.

Inの一次地金の生産量は, 統計より 1999 年以降のデータ が得られた。これらより，採掘・製錬段階のフローについ て, 採掘量と一次地金生産量を推計した. そのため, 採掘時 の尾鉱(鉱石から有用な物質を抽出した後の鉱石)への損失量
あるいは製錬時の残椬への損失量が区別できなかった。

\subsection{In の需要, 消費段階におけるフロー推計}

\subsubsection{In の需要先}

In の用途には, ITO 透明電極, 化合物半導体, 蛍光体, 低融点合金などが挙げられる. 世界での用途別需要量に関す るデータは得られなかったが，日本では透明電極の材料であ る ITO 向け需要量が最も多くを占め，2003 年以降は $85 \%$ 以上の割合を占めている ${ }^{9)}$. ITO 以外の用途は, ITOよりも 多岐にわたる最終製品に用いられるため, 使用後の物質フ ローの推計が困難である。それゆえ，本論文においては， ITO 以外の用途に関しては, 需要量は把握するものの, そ の後のフローは考慮しなかった.

\subsection{2 世界における最終製品別 In 含有量の推計}

世界の ITO 向け In 需要量は, 世界における In 地金生産 量に, 日本に打る ITO 向け需要割合を乗じて 1999 年か ら 2008 年まで推計した。

製品中の素材 (物質) 含有量を推計する手法としては, トッ プダウン手法とボトムアップ手法の 2 つが知られてい る ${ }^{10)}$. トップダウン手法は, 対象とする物質の各製品への 投入量を多年度にわたり把握することで，各年次における社 会中の蓄積量, および廃棄量を推計する手法である. 一方, ボトムアップ手法は, 対象物質を含有する製品の社会中の存 在数抢よびその製品の物質含有原単位を元に, 社会中の蓄積 量を推計する手法である.

ITO 電極は，消費量に対し製造プロセスに打る歩留り が小さいことが知られている4). そのため, ITO 向け In 需 要量から, トップダウン手法により製品中の In 含有量を推 計することはできない，そこで本論文では，ボトムアップ手 法を用いて最終製品中のIn 含有量を推計した.

ITO を透明電極として用いる製品は, 液晶ディスプレイ (Liquid Crystal Display: LCD) 用モジュール(液晶素子), 抒 よびプラズマディスプレイパネル(Plasma～Display Panel: PDP) モジュールであり ${ }^{9)}$ ，ともに中間製品である. 日本に 関しては，これら中間製品の生産数量(個数)を入手でき た ${ }^{11)}$. 一方, 世界に関しては, LCD モジュールおよび PDP モジュールの生産数量, 生産額ともに入手できなかった. そ こで, 詳細なデータのある日本での最終製品別の In 含有量 を推計し, In 含有量と最終製品生産額が比例すると仮定 し, 同じ製品の日本と世界の生産額により，世界の最終製品 別の In 含有量を推計した．ここで, ITO 電極が使われる最 終製品で，世界と日本で生産額を入手できた製品を Table 1 
Table 1 Specified end-use products of ITO in the world and Japan.

\begin{tabular}{ll}
\hline \multicolumn{1}{c}{ World } & \multicolumn{1}{c}{ Japan } \\
\hline Digital TV & LCD TV, PDP TV \\
\hline Laptop PC & Laptop PC \\
\hline LCD monitor & PC display \\
\hline Digital camcorder & Digital camcorder \\
\hline Digital still camera & Digital still camera \\
\hline Mobile phone & Mobile phone, PHS \\
\hline Electric equipment for cars & Navigation system \\
\hline
\end{tabular}

に示す12). 日本では 9 種の最終製品，世界では 7 種の最終 製品となった。他の投入先としては, 医療機器や分析機器な ぞが考えられるが，これらの最終製品に投入された LCD モ ジュール，执よ゙ PDP モジュールについては，モジュール 生産以降の物質フローは考慮しなかった。

世界での最終製品別生産額は，2003 年，2004 年に打け る, 日本, 北米, 欧州, その他の地域の区分での生産額, お よ 2005 年から 2008 年にかけての生産額の 2005 年時点での 予測值が得られた ${ }^{12)}$ 。そのため, 最新の統計值がある 2004 年の In の物質フローを推計した。 また， 2002 年以前につい ては，2003 年における地金生産量と各最終製品中の In 含有 量の比率を，1999 年から 2002 年までに適用し，各最終製 品中の In 量を推計した.

なお，中間製品 (LCD モジュールおよび PDP モジュール) のうちで，最終製品が特定されなかった分（前述した医療機 器や分析機器など)については，日本における対象製品への 投入割合を用いて推計した。 また，日本に打りる投入割合 は，産業連関表から得た LCD モジュールの各最終製品への

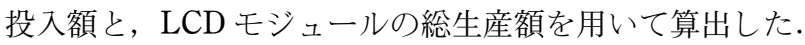

\subsection{3 日本における最終製品別 In 含有量の推計}

ボトムアップ手法を用いるにあたり，2.3.2で示した対象 製品に用いられる液晶の表示部面積, 電極膜厚, ITO 単位 体積当たりの In 含有量が必要である. ITO 単位体積当たり のInの含有量については, 文献 13)より ITO の密度を 7.10 $\mathrm{g} / \mathrm{cm}^{3}, \mathrm{In}_{2} \mathrm{O}_{3}$ の含有率を 90 mass\%として計算した。

電極膜厚は LCD と PDP により異なる．また LCD の中で もアクティブ型 (active-matrix liquid crystal display (LCD)) とパッシブ型 (passive-matrix LCD)により異なる14)ため, それぞれ区分した。さらに，それぞれの分類に扔いて表示部 面積の異なる製品があるため, 生産数量を表示部面積の別に 分類した. Table 2 に本論文で区分した 6 分類を示す.

機械統計 ${ }^{11)} に$ 打ける LCD 生産量は, 1997 年以降, アク ティブ型とパッシブ型それぞれの分類の中に, 細分類が整備 されている.アクティブ型液晶素子は，1997 年から以降は 7.7 型未満と 7.7 型以上に, 2007 年以降はさらに 3.0 型未満, 3.0 型以上 7.7 型未満, 7.7 型以上に分類されている. 本論 文では, 3.0 型未満を小型液晶素子 $($ Small LCD), 3.0 型以上 7.7 型未満を中型液晶素子 (Medium LCD), 7.7 型以上を大 型液晶素子 (Large LCD) と呼ぶこととした。 小型液晶素 子，中型液晶素子の分類がされていない 2006 年以前のデー
Table 2 Types of modules using ITO, specified end-use products and film thickness corresponding to the types.

\begin{tabular}{|c|c|c|c|c|}
\hline \multicolumn{3}{|c|}{ Type of module } & \multirow{2}{*}{ End-use product } & \multirow{2}{*}{ Film thickness } \\
\hline Tech. & Matrix & Size & & \\
\hline \multirow{5}{*}{ LCD } & \multirow{3}{*}{$\begin{array}{l}\text { Active } \\
\text { matrix }\end{array}$} & Large & TV, PC display, Laptop PC & $300 \mathrm{~nm}^{21)}$ \\
\hline & & Medium & $\begin{array}{l}\text { Mobile phone, PHS, Digital } \\
\text { still camera, Digital camcord- } \\
\text { er, Navigation system }\end{array}$ & \multirow{2}{*}{$-100-120 \mathrm{~nm}^{14)}$} \\
\hline & & Small & $\begin{array}{l}\text { Mobile phone, PHS, Digital } \\
\text { still camera, Digital camcord- } \\
\text { er, Projector }\end{array}$ & \\
\hline & \multirow{2}{*}{$\begin{array}{l}\text { Passive } \\
\text { matrix }\end{array}$} & Medium & $\begin{array}{l}\text { Mobile phone, PHS, Digital } \\
\text { still camera, Digital camcord- } \\
\text { er, Navigation system }\end{array}$ & \multirow{2}{*}{$400-500 \mathrm{~nm}^{14)}$} \\
\hline & & Small & $\begin{array}{l}\text { Mobile phone, PHS, Digital } \\
\text { still camera, Digital camcord- } \\
\text { er, Projector }\end{array}$ & \\
\hline & PDP & & TV & $300 \mathrm{~nm}^{21)}$ \\
\hline
\end{tabular}

タは, 2007 年における中型, 小型の生産数比率を, 2006 年 以前も適用するものとした，パッシブ型液晶素子は, 1997 年から液晶モジュールと液晶パネルに分類されている。パッ シブ型液晶素子は，その構造上大型には向いていない15)た め, アクティブ型液晶素子の中型および小型液晶素子の表示 部面積に相当するとした. そのため, 当該年のアクティブ型 液晶素子の中型, 小型の生産数比率を適用した。 な㧍, 液晶 モジュールとは, 液晶パネルに回路基板などを追加したもの であり，表示部面積は液晶パネルと同様と考えた。

アクティブ型大型液晶素子の表示部面積は 7.7 型以上では あるものの，実際の表示部面積に関する情報はない。そこで，

2.3.2で対象とした最終製品のうち，大型液晶素子を用いる 製品を Table 2 のように同定し, 別途 ${ }^{16,17)}$ から製品の表示部 面積を得た.なお，各最終製品の生産数は機械統計11)より 入手した。

中型抢よび小型液晶素子についても，Table 2 のようにそ れぞれを用いる製品を同定した。 中型液晶素子の平均表示部 面積は 5 型, 小型液晶素子の平均表示部面積は 2.5 型とし た. 各最終製品の年次生産数は，アクティブ型とパッシブ型 の区別なく機械統計11)より入手した．ここで，携帯電話に 用いられている液晶素子のアクティブ型/パッシブ型の比 率18)が得られたことから，他の製品についても同じ比率と し，アクティブ型およびパッシブ型を用いている最終製品の 生産台数を推計した．ただし，カーナビゲーションシステム (以降, カーナビ) は中型液晶素子のみを用い19)，プロジェ クターは小型液晶素子のみを用いている20) とした。

PDP モジュールについては，2004 年以降で生産数量の統 計が入手できるが，表示部面積による分類は行われていない。 PDP モジュールを用いる最終製品は, 表示部面積別の構成 比率を入手できたテレビのみを対象製品とした．そこで，ア クティブ型大型液晶素子と同様に，別途文献 21) から製品の 表示部面積を得た.

最後に，需要先製品の特定されなかった LCD モジュール および PDP モジュールに対して，2.3.2で記したように， 生産額を基準として推計した。一方，日本では，LCD モジ ュールおよび PDP モジュールについて，その表示面積区分 
Table 3 Parameters of lifetime distribution function and the average lifetime of end use products.

\begin{tabular}{|c|c|c|c|c|}
\hline \multirow{2}{*}{ End use } & \multicolumn{2}{|c|}{$\begin{array}{l}\text { Parameters in Weibull } \\
\text { distribution function }\end{array}$} & \multirow{2}{*}{$\begin{array}{l}\text { Average } \\
\text { lifespan } \\
\text { (year) }\end{array}$} & \multirow{2}{*}{ Reference } \\
\hline & $\begin{array}{c}\text { Shape } \\
\text { parameter }\end{array}$ & $\begin{array}{c}\text { Scale } \\
\text { parameter }\end{array}$ & & \\
\hline LCD TV/PDP TV & 3.1 & 13 & 12 & 23) \\
\hline PC monitor & 4.8 & 8.4 & 6.7 & 23) \\
\hline Laptop PC & 2.2 & 7.4 & 7.4 & 23) \\
\hline Mobile phone/PHS & 3.1 & 4.8 & 4.3 & 23) \\
\hline Digital camcorder & 3.1 & 7.5 & 6.7 & 24) \\
\hline Digital still camera & 3.1 & 4.0 & 3.6 & 24) \\
\hline Navigation system & 4.0 & 11 & 9.9 & 23) \\
\hline
\end{tabular}

別の生産個数があるため, 生産個数を基準として推計するこ ともできた。このようにして得られた製品中含有量と，ITO 向けに投入された In 量から，生産プロセスにおける歩留ま りを推計することで，既存研究3)の結果と比較した。

\section{4 製品の寿命分布設定}

使用中の製品に含まれる物質ストック量および使用済反製 品に含まれて排出されるIn 量をポピュレーションバランス モデル(Population balance Model: PBM)により分析するた めに，各最終製品の使用年数分布を設定した．各製品の使用 年数分布は, 日本以外の地域のデータが入手困難であっ た22)ため, Table 3 に示した日本のデータを用いた。 なお， 分布形状はワイブル分布である.

液晶テレビ・プラズマテレビは CRT テレビの使用年数分 布を, 液晶ディスプレイは CRT モニタの使用年数分布を用 いた. また，カーナビは自動車と不可分の製品であるため, 自動車の使用年数分布を用いた. ビデオカメラ, デジタルカ メラについては，平均使用年数は得られたが，分布を決定す る形状母数が得られなかった。そこでこれらの製品について は，他の製品群の中で使用傾向が類似していると考えられる 携帯電話の值を転用した。な抢，プロジェクターについて は，平均使用年数に関するデータが入手できなかったこと， 打よび他の製品に比べて生産数, 出荷数ならびに In 使用量 が十分に少ないことから，PBMによる分析対象から除外し た.

\section{5 世界の In の物質フローの構築}

2.2 で得られた採掘・製錬段階でのフローと, 2.3 で得ら れた製品製造段階でのフロー，打よび使用，廃棄段階での物 質ストック量怙よび廃棄フローを元に，世界の In の物質フ ローを構築した。な抢, 現状の廃棄状況から, 使用済及製品 に含まれて排出される Inは,すべて廃棄されるものとし た．最後に，各段階に打ける拡散・散逸としてのフロー量か ら，Inのリサイクル可能量を評価した.

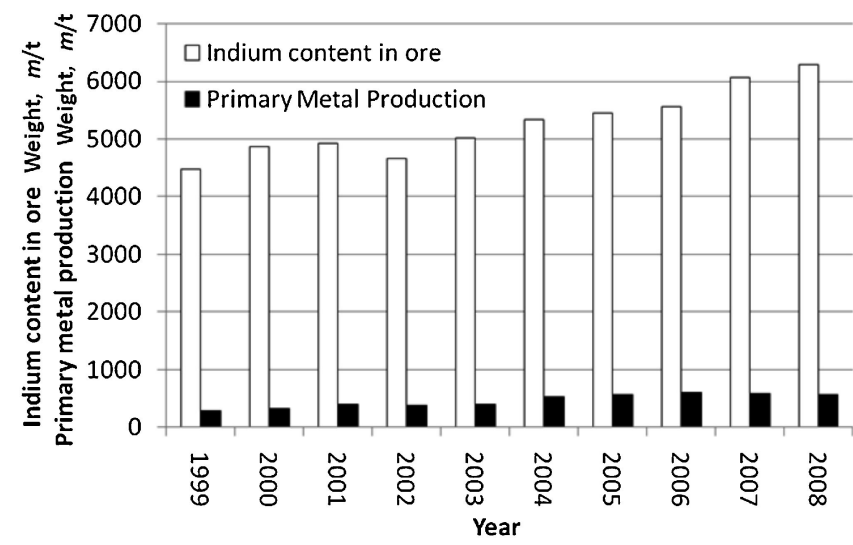

Fig. 2 The amounts of indium contained in annual production of $\mathrm{Zn}$ ore and annual production of primary In metal.

\section{3. 結 果}

\section{1 採掘・製錬時のフロー分析}

文献值 ${ }^{6}$ を元に $\mathrm{In} の \mathrm{Zn}$ 鉱石中の平均含有濃度を求めたと ころ, $39 \mathrm{ppm}$ と推計された. 同様にして Zn の平均含有濃

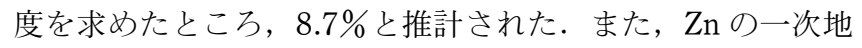
金生産時の歩留まりが $80 \%$ 7) と得られたので，以上の数値に 経年変化がないと仮定して，各年に抢ける鉱石中の In 当量, In一次地金生産量を推計した. その結果を Fig. 2 に示す.

これらの結果から, 1999 年以降, 鉱石からの採掘・製錬 時に打ける, 拡散・散逸による損失分が 9 割程度を占めて いることが分かった。これら損失分は，採掘時の尾鉱，製錬 時のスラッジに含まれていると考えられる.

同様の歩留まりを他の金属に関して推計を行ったところ,

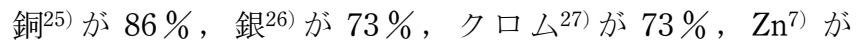
$82 \%$ ，ニッケル28)が $87 \%$ となった．これらの金属に比べて, Inの歩留まりは著しく低いことが明らかになった．

要因として，これらの金属に比べてInの抽出の難しさが 挙げられる. Zn 鉱石の残渣中に含まれるIn を, 酸などの液 体を用いて抽出した上で, 最終的に電解製錬を行って純度を 上げる29)。一方で，現状の需要量に対して一次地金，打よ び二次地金で十分対応できているために，鉱石からの抽出効 率を向上させる必要がないと考えられる.

\section{2 需要段階のフロー分析}

\subsection{1 日本国内における分析結果}

(1) 最終製品中の In 含有量

本論文にて評価対象とした 9 種の最終製品中の In 含有量 を推計した結果を Fig. 3 に示す. 生産量が多く, また面積 の大きい液晶テレビが大半を占めると推計された．また，生 産数は少ないものの, 他の製品よりも平均表示部面積が大き いプラズマテレビが占める割合も大きかった，一方で，PC モニタは, 平均表示部面積は大きいものの, 占める割合は小 さかった。これは, 日本に抢ける生産量が少ないことに起因 すると考えられる. 中型打よび小型液晶素子を用いた最終製 品については, 全体に占める割合が小さいことが分かった。 


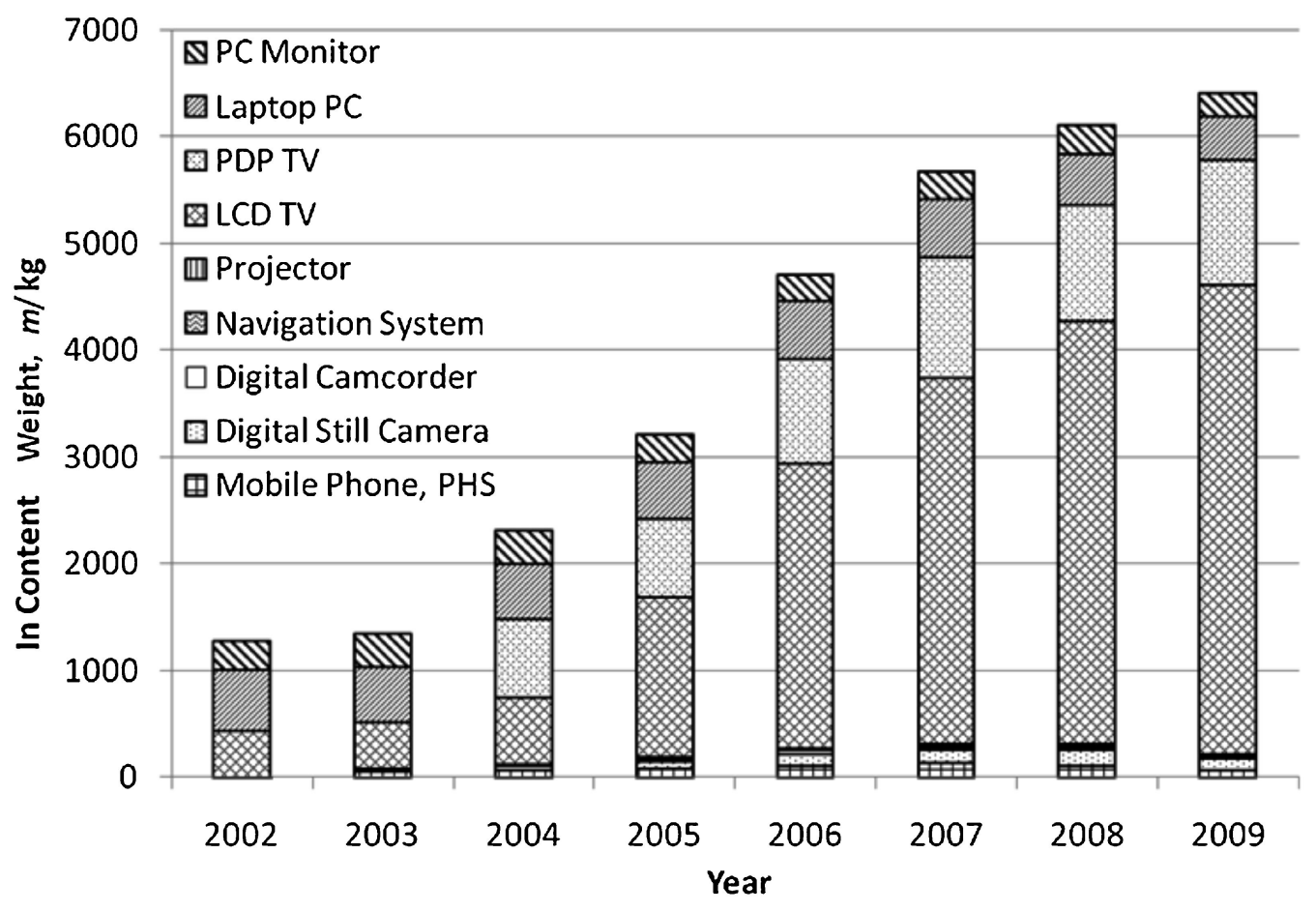

Fig. 3 The amount of indium contained in annual production of the specified end-use products in the form of ITO in Japan.

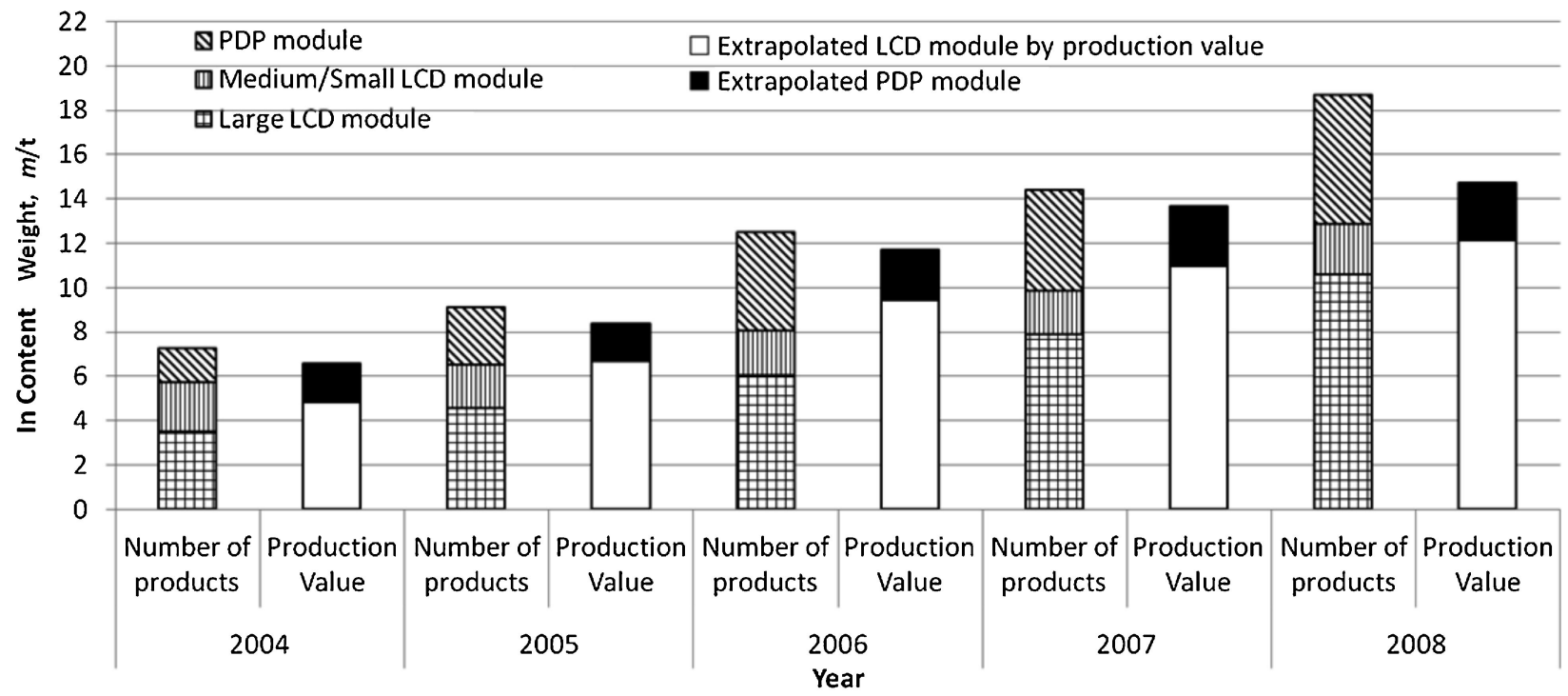

Fig. 4 The amount of indium contained in the all ITO products in Japan extrapolated by two different methods; based on number of products and production value.

\section{(2) 素子(中間製品)中の In 含有量}

2004 年から 2008 年にかけて液晶素子および PDP モジ ュールに関して, 生産個数抢よび生産額を基準にして In 含 有量を推計した結果を Fig. 4 に示す.

生産個数を基準にして推計を行った場合，最終製品へ投入 された大型液晶素子のうち, 本論文にて把握できた割合は約 5 割となった。同様に, 中小型液晶素子, PDP モジュール は，それぞれ 2 割，3 割であった。一方，生産額を基準にし て全液晶素子の対象製品への投入割合を推計した結果は，約 4 割となった。

2 つの手法による結果を比較すると, 生産額を基準に推計 したよりも生産個数を基準にした推計の方が，Inの含有量
が大きく推計されたものの，すべての年で約 $110 \%$ と，大き な差がないことが確認された. 物量に関しては, 生産個数を 基準にし, 大型, 中型, 小型の LCD モジュール, PDP モジ ュールの別に推計した方が妥当な推計手法であると考えられ たが，生産額を基準にした推計によっても，大きな差はない と言える。これから，世界に抏いては 7 種の最終製品につ いて表示部面積別のデータがないため, 日本の生産額を基に した拡大比率を用いて推計したが，日本と世界で生産する最 終製品構成の違いがない前提においては，妥当な推計である.

さらに, 素子中の In 含有量を地金生産量で除し, 生産プ ロセスにおける歩留まりを推計した結果， $2 \%$ 前後となっ た. 既存研究4)では, ITO ターゲットの消費量から各過程で 


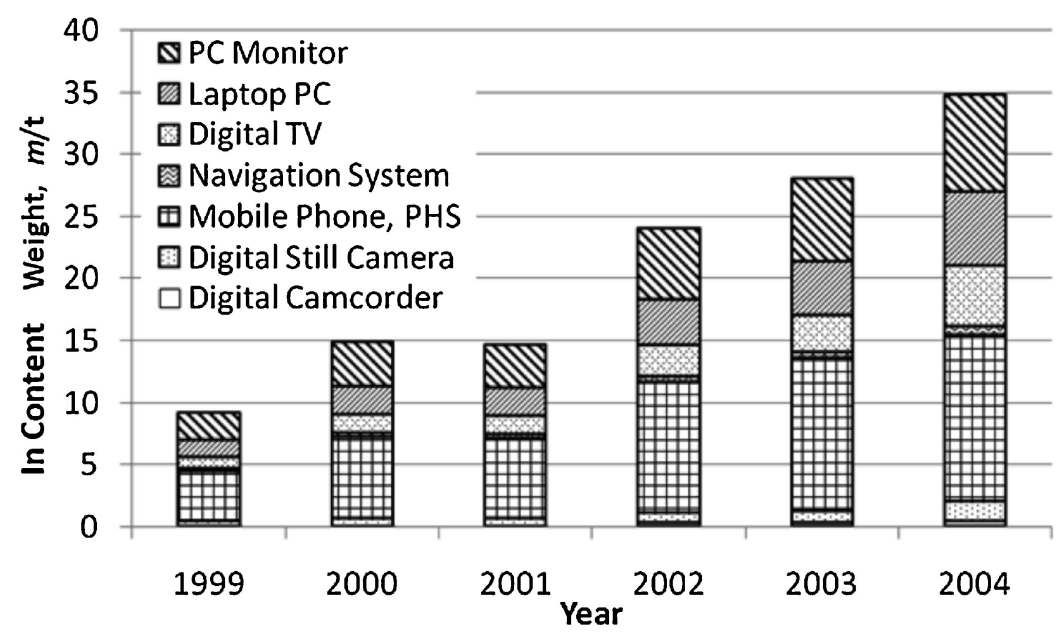

Fig. 5 The amount of indium contained in annual production of the specified end-uses in the world.

の歩留りをヒアリングにより得て，歩留りを $3 \%$ と推計し た．既存研究は，いわゆるトップダウン手法が用いられてい たのに対し，本論文は各最終製品の生産台数とIn 使用原単 位を元に, Inの使用量を推計するボトムアップ手法を用い た. 異なる手法によって, 近い結果が得られたことを確認し た.

\subsection{2 世界の In 需要量}

日本の 9 種の最終製品別 In 含有量をもとに，世界の In 需 要量を推計した結果を Fig. 5 に示す. 1999 年以降, In の需 要量は増加を続け, 2004 年には 3 倍以上になっていた. 特 に, 携帯電話が全体に占める割合が大きく, In 需要量の増 加に大きな影響を与えていることが分かった．また， 2002 年以降は，デジタルテレビ，ノート PC, PC モニタの表示部 の大きな製品による寄与も大きいことが分かった. 日本と同 様に，特定した 7 種の最終製品以外に ITO として使用され た In 量を推計した結果, 2004 年で合計 $82 \mathrm{t}$ と推計された.

\section{3 使用 $\cdot$ 廃棄段階のフロー分析}

7 種の製品について，世界における Inの物質ストック 量, および使用済み製品としての廃棄量を推計した. 1999 年以降の需要量しか推計に用いていないため, 物質ストック 量, 廃棄量ともに携帯電話の平均使用年数を過ぎた 2003 年 と 2004 年の值だけを Fig. 6, Fig. 7 に示す. 1998 年以前の 需要量による影響は反映されていないものの, 年を経るに伴 って増加していることは分かった. 製品の内訳をみると, 物 質ストック量では, 携帯電話・PHS が最も大きな割合を占 め, 廃棄量ではその使用年数の短さもあり 8 割程度を占め ることが分かった. 物質ストック量が携帯電話・PHS に次 いで多かった PC モニタは, 表示部面積が比較的大きいため に全体に占める割合が大きいと考えられた。 また，物質ス卜 ック量では比較的大きな割合を占めるデジタルテレビは, 廃 棄量では著しく小さく推計された.これは, 他の製品と比べ て寿命が長いことに起因すると考えられる.

\subsection{In の物質フローのまとめ}

直近のデータを用いて解析できた，2008 年の日本におけ

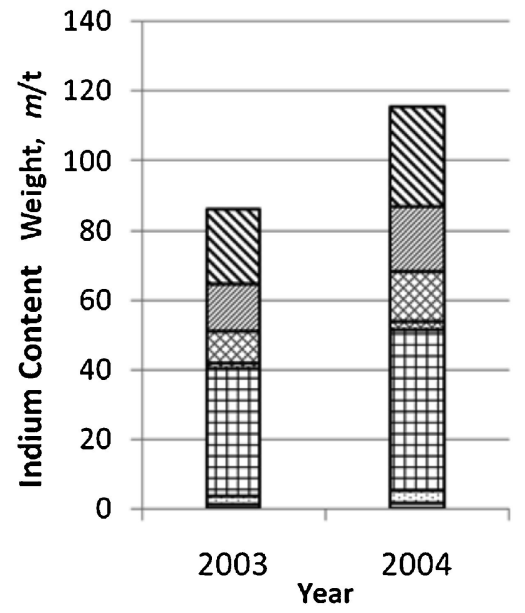

\author{
\$PCMonitor \\ Laptop PC \\ Digital TV \\ Navigation System \\ 由Mobile Phone, PHS \\ 圆 Digital Still Camera \\ $\square$ Digital Camocorder
}

Fig. 6 In-use stock of indium in the specified product enduses in the world.

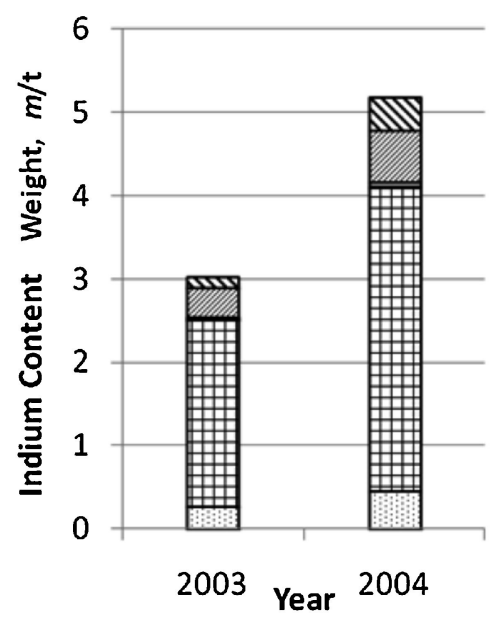

\section{QPC Monitor \\ Laptop PC \\ $\square$ Digital TV \\ 圈 Navigation System \\ 田Mobile Phone, PHS \\ ๑Digital Still Camera \\ $\square$ Digital Camcorder}

Fig. 7 The amount of indium contained in discarded end-oflife products.

るInの物質フローを Fig. 8 に示す. 日本に㧧いて, 一次 地金からは ITO 向けに $234 \mathrm{t}$ の In が投入されている. 二次 地金からの投入量 $517 \mathrm{t}$ を合わせ，合計 $751 \mathrm{t}$ が ITO に投入 


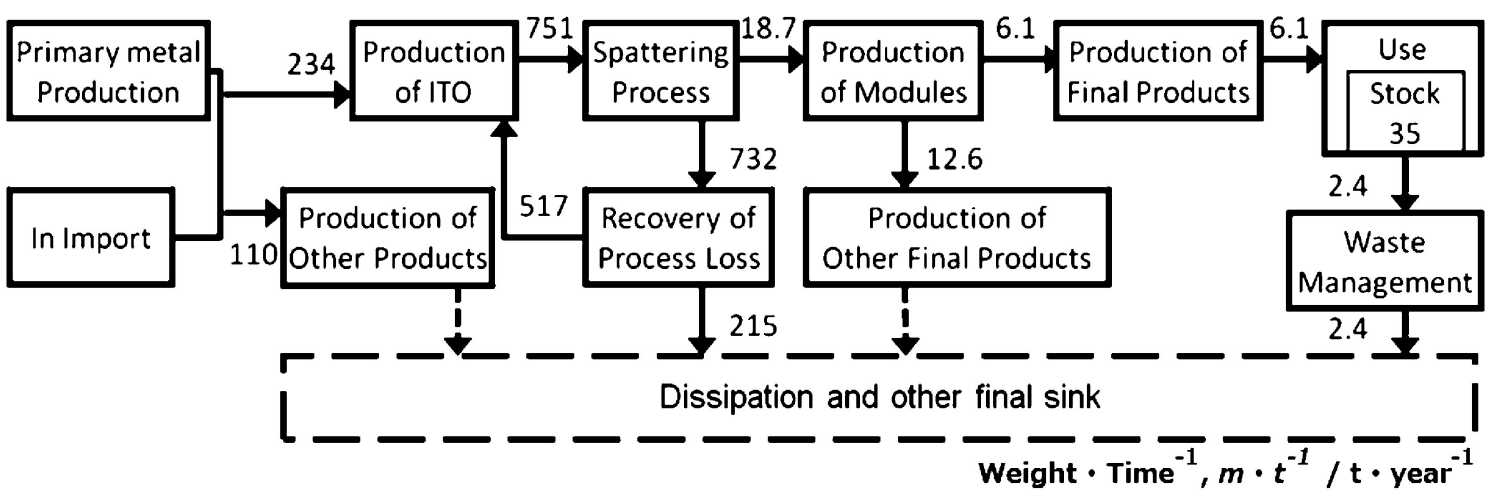

Fig. 8 Substance flow of indium in Japan in 2008.

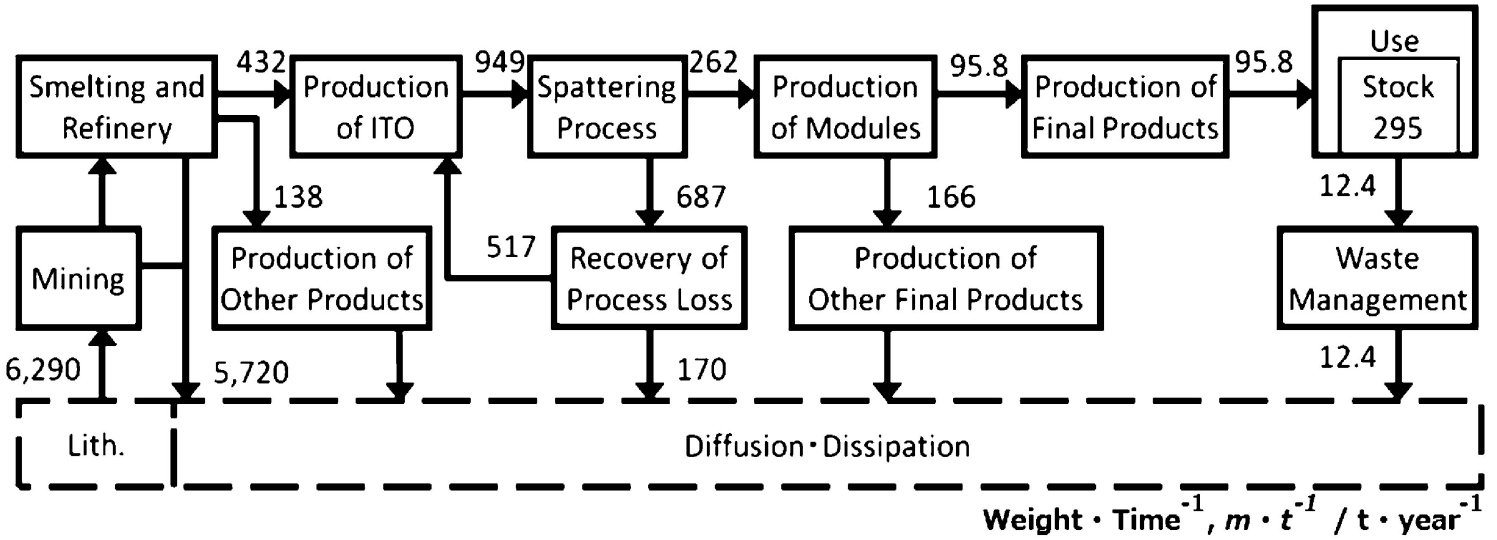

Fig. 9 Substance flow of indium of the world in 2004.

されていると考えられる.この内, 実際に最終製品中に含有 される In 量は $7.2 \mathrm{t} /$ 年であり, 残りの $732 \mathrm{t} /$ 年がプロセス ロスになると推計された。二次地金の生産量が $517 \mathrm{t} /$ 年であ ることから, 回収過程でのロスは $215 \mathrm{t} /$ 年であるという結果 が得られた。 中島らの既存研究3)では，2004 年における二 次地金の製錬ロスが約 5 割とされており，近い結果を得ら れたことを確認した。

Fig. 9 には，2004 年の世界における In の物質フローを示 す。 2004 年における一次地金生産量は $518 \mathrm{t} /$ 年, また二次 地金生産量は $402 \mathrm{t} /$ 年であった. 鉱石中に含まれる In 当量 が $5,344 \mathrm{t} /$ 年であることから，採掘・製錬段階に抢ける拡 散・散逸量は $4,826 \mathrm{t} /$ 年と推計された。これらの地金の内, $87 \%$ に当たる $800 \mathrm{t} /$ 年が ITO 膜の生産プロセスに投入さ れ，それ以外の $120 \mathrm{t} /$ 年が他の用途に投入されると推計され た.

ITO 向けに投入された In の内, 実際に最終製品中に含有 される In 量は $82 \mathrm{t} /$ 年であり, 残りの $710 \mathrm{t} /$ 年がプロセスロ スになると推計された。二次地金の生産量が $402 \mathrm{t} /$ 年である ことから, 回収過程でのロスは $310 \mathrm{t} /$ 年であるという結果が 得られた。

日本におけるプロセス歩留まりは，3.2.2で述べたとおり 1.5\%から 2.5\%であった。一方世界での分析結果は $10 \%$ と なり，日本に拈ける推計值よりも大きくなった．この原因に ついては，以下のようなものが考えられる.
まず，日本の結果を世界に拡大するために，単純に最終製 品の生産額の比率を用いた。 すなわち, 最終製品中で液晶素 子·PDP モジュールの表示部面積については考慮していな い. そのため, この段階で誤差が発生している可能性がある.

また，2.3.2に示したとおり，本論文で詳しく分析を行っ ていない機器については, 金額基準で拡大し, 推計した。こ の比率は，日本における 2005 年のデータを元にしているた め, 実際に各地域における比率を用いていない。たとえば, 分析の対象外とした中で多くを占める医療機器については, 世界に拈ける日本のシェアが $10 \%$ 程度であるのに対し，そ の他の地域は $14 \%$ 程度となっている30). 一方, 分析対象の 最終製品のシェアについては，それぞれ $14 \% ， 52 \%$ となる ため, 医療機器については 2.5 倍程度の誤差が発生している と考えられる. 他の分析対象外の最終製品についても同様の 誤差が考えられるため, 推計值が過大になっていると考えら れる。

以上 2 つ原因により，本論文に抢ける世界の物質フ ローに打ける製品中の In 量は, 過大に推計されている可能 性がある。

1 年に生産される最終製品に含有される In 量 $82 \mathrm{t} /$ 年の 内, 本論文で最終製品を特定した 7 種の製品に含有される In 量は $35 \mathrm{t} /$ 年と推計された. 7 種の最終製品について, 動 的分析した結果, 2004 年には, 物質ストック量は $120 \mathrm{t}$, 廃 棄量は $5.2 \mathrm{t} /$ 年と推計された。 


\subsection{In のリサイクル可能量}

2004 年の In の物質フローの中で, 環境中への In の拡 散・散逸量は, 採掘・製錬時の散逸, リサイクル時のプロセ スロス, 使用済久製品の廃棄の 3 つがある。これらの散逸 量を比較すると, 採掘 - 製錬時が最も大きく $4,800 \mathrm{t} /$ 年, 次 いでリサイクル時のロスが $310 \mathrm{t} /$ 年, 使用済み製品からの廃 棄量はもっとも小さく $5 \mathrm{t} /$ 年と推計された.

リサイクルの促進が可能な量は, 現在回収・利用されずに 廃棄されている量である. 本論文で推計した 3 つ散逸量 は，それぞれ 1 桁以上異なった。採掘・製錬時のリサイク 儿可能量が最も大きく, 地金生産量の 10 倍程度あることが 分かった. よって, 今後の需要増大などに対して安定的な供 給を行うためには，採掘・製錬時の歩留まり向上，あるいは 散逸フローからのリサイクルが有効であることが分かった. また，使用済み製品に含まれるInを全量リサイクルしたと ころで，地金生産量のうち $1 \%$ 程度にしかならないことが分 かった．これは，製品に使用されるまでの工程に拈ける歩留 りが小さいことが主要な要因と考えられる．もう 1 つの要 因として，数年前以前に生産された製品が主に廃棄されるた め, 当期の需要量と比較して, 数年前の需要量が小さかった ことが考えられる. そこで，推計した 2004 年以降も需要量 が増加していることから，2008 年に打ける推計も行った. ただ，世界に抢ける最終製品の生産額が 2005 年時点の見込 み值であったため, スパッタリングプロセス以降のフローに ついて信頼性の低い推計となった。その結果，2008 年にお ける社会中の物質ストック量は $300 \mathrm{t}$ 程度, 廃棄量は $20 \mathrm{t} /$ 年程度と推計された. 2008 年に使用済久製品に含まれる In を全量リサイクルすると, 2008 年の地金生産量のうち $4 \%$ 程度が賄えると推計された. 一方, 採掘 ·製錬時の拡散・散 逸量は $5720 \mathrm{t} /$ 年, プロセスロスが $200 \mathrm{t} /$ 年程度となり, 2004 年の結果と同様の傾向が得られた。需要が増加した 2008 年においても, 採掘 ·製錬時の散逸フローからの回収 が望まれることが分かった。

\section{4. 結 言}

本論文では，世界におけるInの採掘・製錬段階から Inを 使用した製品の廃棄に至るまでの物質フローを推計した．世 界に扔いては，物質フローを把握するための物量に関する統 計は整っていなかったため, 日本のデータを基にして世界の フロー量を推計する手法を構築した。

物質フロー分析の結果から, In が拡散あるいは散逸する フローとして, 採掘・製錬時の散逸, リサイクル時のプロセ スロス, 使用済み製品の廃棄の 3 つのフロー量が把握され た.これら散逸量は, 今後回収促進が可能なリサイクル可能 量と考えられる. 約 $500 \mathrm{t} /$ 年の地金生産量に対し, 採掘・製 錬時の散逸量は約 10 倍あることが分かった。一方，使用済 久製品に含まれるInを全量リサイクルしても, 地金生産量 のうち 2004 年では $1 \%$ 程度, 2008 年の参考值でも $4 \%$ 程度 しか賄えず，リサイクル可能量としては小さいことが分かっ た．使用済久製品からのリサイクルよりも，採掘・製錬時の
散逸フローからの回収が重要であるとの示唆を得た。

本論文を進めるに当たり, 東京大学 岡部徹教授, 野瀬勝 弘特任助教, 大阪産業大学 鈴木晶雄教授, NTT 環境エネ ルギー研究所 高橋和枝博士に貴重なご助言を賜りましたこ とをここに明記し，厚く御礼申し上げます。

文 献

1) Homepage of Electron Devices Lab, Osaka Sangyo Univ., 2007 nendosei no page, Innovation Japan 2007,

http://ms-lab.eic.osaka-sandai.ac.jp/electron/2007/innovation japan.pdf, 2011/1/13.

2) Homepage of Shin-Etsu Polymer Co., Ltd., Investor Relations, Oshirase,

http://www.shinpoly.co.jp/ir/whatsnew/2009/PDF/20090810SEPLEGYDA.pdf, 2010/11/24.

3) R. Kamiki and A. Hosoi: Kikinzoku Rare Metal no Recycle Gijutu Syusei, (NTS Inc., 2007) pp. 397-420.

4) K. Nakajima, K. Yokoyama, K. Nakano and T. Nagasaka: Mater. Trans. 48 (2007) 2365-2369.

5) K. Endo, M. Yamashita, Y. Toba, H. Nakajo, H. Shiba, S. Okumura, Y. Miyahara and K. Takeda: Journal of MMIJ 123 (2007) 123-129.

6) Homepage of Japan Oil, Gas and Metals National Corporation: Supply Side Analysis 20103) -Lead/Zinc-, JOGMEC Virtual Mineral Resource Information Center, http: // www.jogmec.go.jp / mric _ web / kogyojoho/2010-11/ MRv40n4-10.pdf, 2011/1/10.

7) T. E. Graedel, D. van Beers, M. Bertram, K. Fuse, R. B. Gordon, A. Gritsinin, E. M. Harper, A. Kapur, R. J. Klee, R. Lifset, L. Memon and S. Spatari: J. Ind. Ecol. 9(2005) 67-90.

8) Homepage of National Institute of Advanced Industrial Science and Technology, Institute for Geo-Resources and Environment, Green Report 2010, http://unit.aist.go.jp/georesenv/result/green-report/report10/ p71.pdf, $2011 / 3 / 10$.

9) Homepage of Japan Oil, Gas and Metals National Corporation: Kobutsu shigen material flow, Heisei 21nendo chosa report, JOGMEC Virtual Mineral Resource Information Center, http://www.jogmec.go.jp/mric _ web/jouhou/material/2009/ In.pdf, $2010 / 10 / 13$.

10) T. Hirado, I. Daigo, Y. Matsuno and Y. Adachi: Tetsu to Hagane 95 (2009) 96-101.

11) Ministry of Economy, and Industry, Economic and Industrial Policy Bureau, Research and Statistics Department: Yearbook of Machinery Statistics, (1987-2008).

12) Japan Electronics and Information Technology Industries Association, Handotai chosa toukei iinkai, Chuchoki shijo chosa syouiinkai: Sekai no shuyo denshikiki kara mita handoutai shijo no chuchokitembo 2005, (Japan Electronics and Information Technology Industries Association, 2007), pp. 32-33, pp. 3639 , pp. $46-47$, pp. $50-51$, pp. $84-85$.

13) Homepage of Mitsubishi Material Electronic Chemicals Co., Ltd.: Dodensei zairyo, http: // www.mmc-ec.co.jp / business / fine / e01 _ conductive. html \# ito, 2011/1/21.

14) CMC Publishing Co., Ltd.: 2001 nen Ekisho Display kouseizairyo, (2001) p. 108

15) Homepage of Science Graphics Co., Ltd.: LCD no kozo, kisogenri, 2011/3/10.

16) Homepage of Ministry of Economy, Trade and Industry Commerce and Information Policy Bureau, Information and Communication Electronics Division: Television juzouki no genjo ni tsuite, http://www.meti.go.jp/ committee / materials2 / downloadfiles / g81111a05j.pdf, 2010/12/10.

17) Homepage of Japan Electronics and Information Technology Industries Association, Information Terminals and Technologies Committee, Display Senmon Committee: Ekisho monitor oyobi Note PC you Ekisho Display no shijokibo mitoshi ni tsuite, http: / home.jeita.or.jp / is / statistics / intelterm / 2009/1008251 display.pd, $2010 / 12 / 10$.

18) Y. Kim: Keiei Shirin 41(2004) 107-116.

19) Homepage of Impress Watch Corporation, Car Watch, 
http://car.watch.impress.co.jp/docs/news/20100511_366353. html, 2011/3/10.

20) Homepage of Quartz Crystal Industry Association of Japan: Ekisho Projector

http://www.qiaj.jp/pages/frame20/docs/handbook-projector01.pdf, $2011 / 3 / 10$.

21) Yano Research Institute Ltd.: Raremetal 2020 nen tenbo, Jidosha sangyo, Shoene sangyo, Electronics sangyo, Bunyabetsu juyou jittai to choki juyou yosoku, (Yano Research Institute Ltd., 2010) p. 260.

22) Homepage of National Institute for Environmental Studies: Lifespan Database for Vehicles, Equipment, and Structures, http://www.nies.go.jp/lifespan/index.html, 2011/3/10.

23) M. Oguchi, T. Kameya, T. Tasaki, N. Tamai and N. Tanigawa: Waste Management Research 17 (2006) 50-60.

24) Cabinet Office, Economic and Society Research Institute, Department of Business Statistics: Kakeishohi no doko, Shohi doko chousa nempou 2008, (Toko Co., Ltd. 2008).

25) T. E. Graedel, D. Vanbeers, M. Bertram, K. Fuse, R. B. Gordon,
A. Gritsinin, A. Kapur, R. J. Klee, R. J. Lifset, L. Memon, H. Rechberger, S. Spatari and D. Vexler: Environ. Sci. Technol. 38 (2004) 1242-1252.

26) J. Johnson, J. Jirikowic, Marlenbertram, D. Vanbeers, R. B. Gordon, K. Henderson, R. J. Klee, T. Lanzano, R. Lifset, L. Oetjen and T. E. Graedel: Environ. Sci. Technol. 39(2005) $4655-4665$

27) J. Johnson, L. Schewel and T. E. Graedel: Environ. Sci. Technol. 40 (2006) 7060-7069.

28) B. K. Reck, D. B. Muller, K. Rostkowski and T. E. Gradel: Environ. Sci. Technol. 42(2008) 3394-3400.

29) T. H. Okabe and K. Nose: OHM $97(2010) 38-47$.

30) Homepage of JMA Research Institute Inc.: Shiryou3, Iryou kiki sangyou no genjou, Iryou kiki bunya heno sannyu, buzai kyoukyu no kasseika ni muketa kenkyukai (dai 2 kai), haifu shiryou,

http: // www.meti.go.jp/ committee / materials2 / downloadfiles / g90119c02j.pdf, 2011/3/10 